\title{
Delphi assessment of audit and research priorities in an emergency department.
}

Sinéad M O'Donnell MD ${ }^{1}$, Anna Carison ${ }^{1}$, Jessica Adams ${ }^{1}$, Elliot Long PhD ${ }^{1,2}$, Franz E Babl MD $1-3$

${ }^{1}$ Royal Children's Hospital, Melbourne.

Address: Emergency Department, Royal Children's Hospital, 50 Flemington Rd, Parkville, VIC, 3052, Australia.

${ }^{2}$ Murdoch Children's Research Institute, Melbourne.

Address: 50 Flemington Rd, Parkville, VIC, 3052, Australia.

${ }^{3}$ Department of Paediatrics, Faculty of Medicine, Dentistry and Health Sciences, University of Melbourne, Melbourne.

Address: Grattan St, Parkville, VIC, 3010, Australia.

AUTHOR'S CONTRIBUTIONS: AC and SOD submitted the ethics application. SOD, AC, JA and EL recruited participants. SOD and $A C$ completed the data entry and revision of this data. SOD, AC, JA, EL and FEB reviewed and amended the project protocol as appropriate and prepared the audit and research topics titles for the second survey. FEB conceived the idea of the project, reviewed data and edited the written versions of the paper.

RUNNING TITLE: Audit and research priorities in an ED.

ADDRESS OF RECRUITING INSTITUTION: Royal Children's Hospital, 50 Flemington Rd, Parkville, VIC, 3052, Australia.

\section{CORRESPONDING AUTHOR:}

Dr. Sinéad O'Donnell

Emergency Department

Royal Children's Hospital

Flemington Rd

Parkville

Victoria 3052

Australia

Phone 61393456153

Fax 6139345600

Email sinead.o'donnell@rch.org.au

This is the author manuscript accepted for publication and has undergone full peer review but has not been through the copyediting, typesetting, pagination and proofreading process, which may lead to differences between this version and the Version of Record. Please cite this article as doi: $10.1111 / 1742-6723.13453$

This article is protected by copyright. All rights reserved. 
WORD COUNT: Abstract: 236

Main Text: 2,344 (excluding figures, tables and references)

This article is protected by copyright. All rights reserved. 


\title{
Delphi assessment of audit and research priorities in an emergency department.
}

\author{
Abstract \\ Objective \\ Audit and research projects in the emergency department (ED) are important to \\ improve patient care but can be time and resource consuming. We identified and \\ prioritised audit and research topics among multidisciplinary ED staff to fill perceived \\ knowledge gaps, encourage engagement, reduce duplication, and facilitate \\ translation of evidence into clinical practice.
}

\section{Methods}

A two-stage electronic Delphi survey process was undertaken by senior medical, nursing, education and social work staff at the Royal Children's Hospital, Victoria. Survey one collected demographic data and audit and research ideas following a series of open-ended questions. Priority themes were defined as those that had $\geq \mathbf{4}$ responses. Survey two used a 7-point Likert ranking of these themes to generate a departmental audit and research prioritisation list.

\section{Results}

$72 / 89$ (82\%) available senior staff responded to survey one and 63/83 (76\%) responded to survey two. Survey one yielded 208 audit and 130 research topics.

This article is protected by copyright. All rights reserved. 
Survey two established a prioritised list of 17 audit and 14 research topics. Top audit themes were mental health care, patient flow, management of sepsis and delays in ED specialist referrals. Top research priorities were the management of sepsis, mental health care, management of patients with autism and the management of severe asthma.

\section{Conclusions}

This Delphi study has provided departmental audit and research priorities that are perceived to be of importance across the multidisciplinary ED team. This methodology allows strategic allocation of limited resources and may increase staff engagement.

\section{Key words}

Audit, Delphi, emergency department, research and survey.

This article is protected by copyright. All rights reserved. 
Introduction

Audit and research processes are critical to improving care and furthering the knowledge base of the physicians and other multidisciplinary staff who practice in emergency medicine and paediatric emergency medicine (PEM). Audit has been defined" as "systematic review of elements of clinical care against predetermined criteria, with the aim of identifying areas for improvement and then developing, implementing and evaluating strategies intended to achieve that improvement." The National Health and Medical Research Council (NHMRC) defines research as a body of work which "includes at least investigation undertaken to gain knowledge and understanding or to train researchers." ${ }^{2}$

Both processes are important and can lead to improvements in patient safety and clinical care. They also can produce hypothesis generating insights, contributing to increased knowledge, improved patient care and further research. The terms audit and research may overlap to a degree. There are key similarities between them including methodologies, design, answering important or relevant questions and systematic data collection. Furthermore they may work as a continuum of each other; what may begin as an audit evaluation may evolve into research. However many differences exist also. The primary focus of an audit is quality assurance, benchmarking a current practice against an ideal standard and safe guarding high 
standards of clinical care. ${ }^{3}$ The primary focus of a research project is the generation of new knowledge and/or testing of hypotheses. This type of work is particularly relevant when there is unclear evidence on a topic or the evidence is limited.

In some jurisdictions students, doctors and doctors-in-training are expected or required to complete audits to maintain their professional competence and training requirements. ${ }^{3,4}$, Furthermore completing an audit is now considered one of the pillars of clinical governance ${ }^{5}$ and a 2012 Cochrane systematic review indicated an overall positive effect of completing audits on daily clinical practice. ${ }^{6}$

Inclusion of health care staff in the development of audit and research questions and priorities is important. A study in 2009 estimated that $85 \%$ of medical research was inefficient or wasteful with one of the main areas of deficiency being whether the research question was relevant for patients or clinicians. ${ }^{7}$ A national list of research priorities in PEM in Australia and New Zealand has been developed previously ${ }^{8}$ but nursing and allied health members of staff were not consulted. Developing a list of audit and research priorities within an emergency department (ED) would create priorities important to the local treating clinicians and better guide departmental efficiencies in designing and completing projects.

This article is protected by copyright. All rights reserved. 
Undertaking audit and research in the emergency department (ED) has challenges. Within PEM specifically, these include low rates of serious emergency presentations resulting in difficult attainment of necessary study numbers, additional obstacles with ethics approval and consent in emergency cases, difficult procurement of samples in children and variability in departmental practices and experience across different types of EDs who see children.

Audit and research in EDs is often conducted with limited resources and funding and frequently by time-poor clinicians or other ED staff. This can be managed by developing a strong interested team of individuals, structuring audit and research designs, identifying realistic goals and ensuring the work meets the local departmental needs and goals. Australian paediatricians and paediatric emergency physicians are interested in research and developing research priorities nationally. ${ }^{8,9}$

The primary aim of this study was to identify and prioritise the departmental audit and research questions of a multidisciplinary team at a large urban ED.

\section{Methods}

The study was conducted in The Royal Children's Hospital (RCH) in Melbourne, Australia, a large tertiary PED with an annual census of 90,000 children. $\mathrm{RCH}$ is the sole statewide-designated paediatric trauma centre in Victoria. It has approximately

This article is protected by copyright. All rights reserved. 
80 medical staff at all levels, 150 nurses and 6 social workers. We conducted a two stage modified Delphi survey of audit and priorities that are perceived by all senior medical, nursing and education staff and social workers in the ED. The audit was approved by the ethics committee at Royal Children's Hospital (approval number HREC/18/RCHM/116). Our methodology was modelled on similar surveys conducted by national and international research networks including Paediatric Research in Emergency Departments International Collaborative (PREDICT) ${ }^{8}$, Paediatric Emergency Research in the UK and Ireland (PERUKI) ${ }^{10}$ and the Australian Paediatric Research Network (APRN) ${ }^{9}$. A Delphi study is a multistage process, which mediates and collates group consensus on chosen topics. ${ }^{11}$ It has been widely used as an accepted research methodology in other clinical prioritisation studies. Senior departmental staff was defined as the following staff groups regardless of part-time or full-time status: fellows and consultants, nurse unit manager, associate unit managers, clinical nurse specialists, clinical nurse educators, nurse practitioners (candidates and endorsed) and social work team. An initial pilot survey was developed and piloted across all craft groups and amended accordingly. This formed the basis for the first survey of audit and research ideas.

Stage 1: The first, paper based, survey was anonymous and extracted demographic data including craft group, years of experience as a clinician, years of experience in RCH ED and current academic appointment. In survey one participants were invited

This article is protected by copyright. All rights reserved. 
to list up to 5 audit topics and 5 research questions of any format and topic and not strictly in the PICO format. The survey had open-ended questions to allow suggestion of ideas. The following question was posed to all participants: 'Thinking about your practice, what are the most important audit topics we should audit in the department? (List up to 5 topics; ideally try to be as specific as possible)'. The same question was posed to participants about potential research topics. These ideas were then collated and grouped into broad categories. Those that had $\geq 4$ responses were put forward for review by senior staff in survey two. Where necessary, the research group reworded the questions into more applicable audit and research terms prior to survey two being distributed.

Stage 2: Survey two was web-based (SurveyMonkey Inc. San Mateo, California, USA. www.surveymonkey.com). Participants were asked to prioritise in order of importance the list of audit and research priorities identified from survey one. The following question was asked: 'Thinking about your clinical practice, how important are the following questions to you in terms of need for future audit or future research?'. A 7-point Likert scale of prioritisation was used with points of reference including: not a priority, low priority, somewhat priority, neutral, moderate priority, high priority and essential priority used. Likert scores were merged for analysis with a mean score calculated for each question. Based on the mean scores we then prioritised the topics for audit and research.

This article is protected by copyright. All rights reserved. 
In both surveys staff were excluded if on leave during the study period and an option was given to identify themselves if interested in conducting specific audit/research once the study was completed. Two weekly reminders were sent via email and staffs were verbally reminded at senior staff meetings. Consent was implied when the participant responded to the survey.

\section{Results}

Survey one opened on March $28^{\text {th }} 2018$ and closed on April $18^{\text {th }} 2018$. Survey two opened on June $5^{\text {th }} 2018$ and closed on July $31^{\text {st }} 2018$. There was an $82 \%$ response rate to survey 1 and 76\% response rate to survey 2 (Figure 1). All craft groups within the department were represented in the responses to survey one including consultants (20), fellows/senior registrars (10), associate nurse unit managers (10), education team members (5), clinical nurse specialists (10), nurse practitioners (6) and social workers (5). Six respondents did not identify their craft group. The participants had a mean of 15.6 years experience as a clinician (Table 1). Eighteen participants (20\%) currently held an academic role.

\section{Survey one.}

A total of 208 audit topics and 130 research topics were generated from survey one. This was a mean of 2.8 and 1.8 audit and research questions respectively per person. All participants submitted at least one question. Forty-five audit topics and $\mathbf{2 3}$

This article is protected by copyright. All rights reserved. 
research topics were duplicated in responses. Therefore 17 audit questions and 14 research questions that had received $\geq 4$ responses were identified.

\section{Survey two.}

Mean scores for the 17 audit questions ranged from 4.1 to 5.9 (rated 1-7) and mean scores for the 14 research questions ranged from 4.4 to 5.5 (rated 1-7). See table 2. The top ranked audit questions from survey two included the current management issues and flow processes in the care of mental health patients, the effect a front of house team is having on ED management and flow, management of sepsis in the ED and factors affecting specialist review in the department. The top ranked research questions included care of patients with autism spectrum disorder, intravenous treatments for patients with severe asthma, fluid resuscitation in patients with sepsis, training of staff in the management of mental health patients and factors that contribute to patients/carers seeking ED treatment .

\section{Discussion}

We undertook a systematic process to assess audit and research priorities in a large urban ED. The audit and research priorities thathave emergedare indicative of the issues affecting ED staff, the diseases presenting to a paediatric ED, or where evidence is perceived to be missing or limited. To avoid the bias of an audit and

This article is protected by copyright. All rights reserved. 
research agenda driven by departmental leadership or academics we invited all multidisciplinary senior staff - including senior nurses, educators, nurse practitioners, social workers, consultants and fellows - and aimed to determine both an audit and research agenda most relevant for local ED staff.

There were a number of topics identified that were viewed as equally important amongst respondents. Top audit topics were mental health care (delays, management), improvements in patient flow, management of sepsis and delays in ED specialist referrals. Top research priorities were the management of sepsis, mental health care, management of patients with autism and management of severe asthma. There are some similarities in the research topic findings between this study and that from the PREDICT and PERUKI networks. ${ }^{8,10}$ Topics which appeared in both lists included resuscitation, severe asthma and sepsis management, diagnostic ultrasound use in the ED and factors driving attendance for care at an ED. Most notably no mental health topics featured on the PREDICT or PERUKI lists and yet they feature prominently in the top 5 for both audit and research priorities in our study. The PREDICT and PERUKI studies surveyed senior medical staff only. Our study included all senior medical and nursing staff and allied health team members. ED mental health presentations are increasing in frequency, acuity and resource utilisation year on year ${ }^{12}$ and are obviously perceived as an important issue locally to all members of the team. There is no similar data to compare our audit findings to.

This article is protected by copyright. All rights reserved. 
The top five audit priorities from this study are now targets of quality assurance processes within the department and the top 5 research priorities have had relevant research projects initiated.

A national study in Australia and New Zealand to determine research priorities across the PREDICT research network was recently undertaken. ${ }^{8}$ While useful to set a national research agenda, it was limited to senior medical staff and exclusively focused on new evidence generation. The PREDICT study deliberately excluded topics where the authors thought evidence already existed ( $48 \%$ of all research topics suggested in the initial survey). In this Delphi study we deliberately did not exclude any topics from prioritisation; if evidence exists, it will need to be promulgated to ED staff through staff education and guideline updates. If no evidence exists, or existing evidence is perceived as not applicable in the local setting, then this evidence should be generated. The findings of our study are broader than previous studies due to both the inclusion of the MDT and the incorporation of audit as well as research topics. Our study found there was not much variability in terms of the mean importance of each audit and research question. The ED staff collectively viewed a wide range of topics as equally important and perceived knowledge gaps in multiple areas relevant to clinical care.

This article is protected by copyright. All rights reserved. 
This methodology could be repeated in other departments. It was relatively easy and quick to undertake. Additional free text comments were generated within each survey. These comments will be beneficial in providing context for priority topics, identify interested staff, determine if initial work has already been done or is considered by ED staff, inform about existing evidence or giving recommendations for future work. Our response rate for both surveys was much higher than previous similar Delphi studies $8,9,10$ indicating departmental staff buy-in and enthusiasm for inclusion in such a project.

The broad topics prioritised in our study represent the varied backgrounds of the participants. This study allows the setting of a deliberate audit and research agenda for the department, maximising the use of limited resources and funding, helping to minimise duplication of work and providing a list of topics for junior staff to participate in and be supported. To our knowledge a departmental survey such as this has not been described in the ED literature.

\section{Limitations}

This study took place in one regional tertiary PED only. However we believe that the findings of this study may be relevant for other paediatric EDs in Australia and New Zealand. We did not include patients and carers. One UK based study included clinicians, patients and caregivers in their prioritisation study..$^{13}$ Their wide list of

This article is protected by copyright. All rights reserved. 
prioritised research ideas is not that different to our findings. Another Delphi study by Furyk et $\mathrm{al}^{14}$, examining consensus research priorities for patients with status epilepticus (SE), also included health consumers in their participant cohort. They also identified 9 research questions, which were shared between the health experts and the health consumers in the treatment of SE perhaps suggesting that there may be considerable similarities between clinician and health consumer priorities. We deliberately kept the initial and follow up survey enquiries broad and not disease specific.

\section{Conclusions}

This Delphi study has provided audit and research priorities which are of departmental importance across the multidisciplinary ED team. This methodology has the potential to identify longer-term departmental audit and research priorities, increase staff buy-in by focusing on topics perceived as important, and provide a prioritised list of audit and research topics for ED staff which in turn has the potential to improve the quality and quantity of audit and research produced by our department.

\section{Acknowledgements}

We would like to thank the participating emergency department staff.

This article is protected by copyright. All rights reserved. 


\section{Funding}

The study was unfunded. FEB's time was part funded by a grant from the Royal Children's Hospital Foundation, Melbourne, Australia, a Melbourne Children's Clinician Scientist Fellowship, Melbourne, Australia; and an NHMRC Practitioner Fellowship, Canberra, Australia.

\section{References}

1. Department of Health and Human Services. Partnering for Performance guide. 2010. Accessed on 01/02/2019. Available from: https://www2.health.vic.gov.au/about/publications/policiesandguidelines/pa rtnering-performance-guide

2. National Health and Medical Research Council, the Australian Research Council, Universities Australia. The National Statement on Ethical Conduct in Human Research. 2018. Accessed on 01/02/2019. Available from: nhmrc.gov.au

3. Benjamin A. Audit: how to do it in practice. BMJ. 2008 May 31;336(7655):1241-5.

4. Tasker F, Thomson K. How to set up an audit. BMJ. 2012;344:e3423.

This article is protected by copyright. All rights reserved. 
5. Australian Commission on Safety and Quality in Health Care. National Model Clinical Governance Framework. 2017. Accessed on 01/02/2019. Available from:

https://www.safetyandquality.gov.au/sites/default/files/migrated/NationalModel-Clinical-Governance-Framework.pdf

6. Ivers N, Jamtvedt G, Flottorp S, et al. Audit and feedback: effects on professional practice and healthcare outcomes. Cochrane Database Syst Rev 2012;6:CD000259.

7. Chalmers I, Glasziou P. Avoidable waste in the production and reporting of research evidence. Obstet Gynecol. 2009 Dec;114(6):1341-5.

8. Deane $\mathrm{HC}$, Wilson $\mathrm{CL}$, Babl FE, et al. PREDICT prioritisation study: establishing the research priorities of paediatric emergency medicine physicians in Australia and New Zealand. Emerg Med J. 2018 Jan;35(1):39-45.

9. Rudoph $\mathrm{S}$, Hiscock $\mathrm{H}$, Price $A$, et al. What research questions matter to Australian paediatricians? National Delphi study. J Paediatr Child Health. 2009 Dec;45(12):704-10.

10. Hartshorn S, O'Sullivan R, Maconochie IK, Bevan C, Cleugh F, Lyttle MD. Establishing the research priorities of paediatric emergency medicine clinicians in the UK and Ireland. Emerg Med J. 2015 Nov;32(11):864-8.

11. Hasson F, Keeney S, McKenna H. Research guidelines for the Delphi survey technique. J Adv Nurs. 2000 Oct;32(4):1008-15.

This article is protected by copyright. All rights reserved. 
12. Hiscock H, Neely RJ, Lei S, Freed G. Paediatric mental health presentations to emergency departments, Victoria, 2008-15. Med J Aust. 2018;208: 343-348.

13. Smith J, Keating L, Flowerdew L, et al. An emergency medicine research priority setting partnership to establish the top 10 research priorities in emergency medicine. Emerg Med J. 2017 Jul;34(7):454-456.

14. Furyk J, Ray R, Watt K, et al. Consensus research priorities for paediatric status epilepticus: A Delphi study of health consumers, researchers and clinicians. Seizure. 2018 Mar;56:104-109.

This article is protected by copyright. All rights reserved. 
Tables

Table 1. Participant's clinical and emergency experience

\begin{tabular}{|lccc|}
\hline & Total (years) & Range (years) & Mean (years) \\
Years as a clinician & 1042 & $4-45$ & 15.6 \\
Years in emergency & 766 & $1.5-29$ & 11.1 \\
Years in RCH & 552 & $0-23$ & 7.9 \\
\hline
\end{tabular}

Table 2. Audit and research questions in order of priority.

\begin{tabular}{|c|c|c|c|}
\hline & Audit Questions & $\begin{array}{l}\text { Mean } \\
\text { scores }\end{array}$ & $\begin{array}{l}\text { Standard } \\
\text { Deviation }\end{array}$ \\
\hline 1 & $\begin{array}{l}\text { What is the average length of stay in } E D^{+} \text {for patients with mental } \\
\text { health issues? What are the identified reasons for delayed review / } \\
\text { discharge? }\end{array}$ & 5.97 & 1.07 \\
\hline 2 & $\begin{array}{l}\text { What is the current management of patients presenting with mental } \\
\text { health issues? (Patient flow, referral, disposition, follow up) }\end{array}$ & 5.81 & 1.18 \\
\hline 3 & $\begin{array}{l}\text { What is the impact of RAPID (front of house team) on } E D^{+} \text {flow, } \\
\text { investigation and management? }\end{array}$ & 5.60 & 1.04 \\
\hline 4 & $\begin{array}{l}\text { What is the current management of sepsis in } E D^{+} \text {? (Frequency of } \\
\text { patients with sepsis, number of patients with sepsis who receive a } \\
\text { sepsis workup / antibiotics / fluids / inotropes, time from } \\
\text { presentation to sepsis treatment) }\end{array}$ & 5.43 & 1.07 \\
\hline 5 & $\begin{array}{l}\mathrm{ED}^{+} \text {Specialist referrals - what is the length of time between referral } \\
\text { and review? What are the reasons behind delays in review? }\end{array}$ & 5.13 & 1.29 \\
\hline 6 & $\begin{array}{l}\text { Flow of admitted patients - what is the length of time from bed } \\
\text { request to patient discharged from } E D^{+} \text {? What are the factors that } \\
\text { determine length of stay of admitted patients in } E D^{+} \text {? }\end{array}$ & 5.00 & 1.37 \\
\hline 7 & $\begin{array}{l}\text { What are the current pain management practices in } \mathrm{ED}^{+} \text {? (Type and } \\
\text { dose of analgesia prescribed for different presenting complaints, } \\
\text { time from presentation to administration of analgesia) }\end{array}$ & 4.95 & 1.35 \\
\hline 8 & $\begin{array}{l}\text { What is the success rate for gaining intravenous access in } E D^{+} \text {? What } \\
\text { is the time to gaining intravenous access in } E D^{+} \text {? }\end{array}$ & 4.74 & 1.13 \\
\hline 9 & $\begin{array}{l}\text { What is the incidence of adverse outcomes in patients with fractures } \\
\text { who are referred to fracture clinic? }\end{array}$ & 4.73 & 1.37 \\
\hline 10 & $\begin{array}{l}\mathrm{ED}^{\dagger} \text { short stay unit - what is the rate of failed admissions? How many } \\
\text { patients have an appropriate criteria led discharge completed? }\end{array}$ & 4.71 & 1.13 \\
\hline 11 & $\begin{array}{l}\text { What is the re-presentation rate following use of low-dose } \\
\text { dexamethasone to treat mild-moderate severity croup (not requiring } \\
\text { adrenaline)? }\end{array}$ & 4.68 & 1.31 \\
\hline 12 & $\begin{array}{l}\text { What is the frequency and type of adverse events in children } \\
\text { undergoing procedural sedation in } E D^{+} \text {? }\end{array}$ & 4.66 & 1.29 \\
\hline 13 & $\begin{array}{l}\text { Dexamethasone dose in children presenting to } \mathrm{ED}^{+} \text {with croup } \\
\text { symptoms - what is the variance in dosing? What factors contribute } \\
\text { to this variance? }\end{array}$ & 4.62 & 1.42 \\
\hline
\end{tabular}




\begin{tabular}{|c|c|c|c|}
\hline 14 & $\begin{array}{l}\text { What is the current pre-arrival trauma team management? (Role } \\
\text { allocation, team preparation, pre-ordering of investigations and } \\
\text { imaging) }\end{array}$ & 4.43 & 1.20 \\
\hline 15 & $\begin{array}{l}\text { POCUS }^{\ddagger} \text { use in ED } D^{\dagger} \text { - what is the current frequency of POCUS }{ }^{\ddagger} \text { use? } \\
\text { What is POCUS } \\
\text { currently used for? }\end{array}$ & 4.43 & 1.20 \\
\hline 16 & $\begin{array}{l}\mathrm{CRP}^{\S} \text { use in } \mathrm{ED}^{+} \text {- what is the frequency of ordering a } \mathrm{CRP}^{\S} \text { in } \mathrm{ED}^{+} \text {? Is } \\
\text { there a correlation with certain clinical presentations? }\end{array}$ & 4.22 & 1.40 \\
\hline \multirow[t]{2}{*}{17} & $\begin{array}{l}\mathrm{CT}^{\natural} \text { brain in head injured patients in } \mathrm{ED}^{+}-\mathrm{CT}^{\natural} \text { brain rate for these } \\
\text { patients - time from presentation to } \mathrm{CT}^{\natural} \text { brain. }\end{array}$ & 4.19 & 1.30 \\
\hline & Research Questions & & \\
\hline 1 & $\begin{array}{l}\text { What volume of fluid resuscitation prior to initiating inotropes is } \\
\text { associated with the best patient outcome? }\end{array}$ & 5.54 & 1.06 \\
\hline 2 & $\begin{array}{l}\text { Does training in the management of mental health emergencies } \\
\text { translate to better patient care? }\end{array}$ & 5.43 & 1.13 \\
\hline 3 & $\begin{array}{l}\text { What is the best way to care for, support and treat patients with } \\
\text { autism spectrum disorder in the ED? What are the challenges? }\end{array}$ & 5.41 & 1.17 \\
\hline 4 & $\begin{array}{l}\text { What intravenous therapies for severe asthma are associated with } \\
\text { improved patient outcomes? }\end{array}$ & 5.33 & 1.45 \\
\hline 5 & $\begin{array}{l}\text { What factors contribute to patient's / carer's decision to seek } \\
\text { medical attention in an } E D^{\dagger} \text { ? }\end{array}$ & 5.32 & 1.19 \\
\hline 6 & How can staff wellbeing be measured / improved? & 5.13 & 1.33 \\
\hline 7 & $\begin{array}{l}\text { Is simulation associated with improvement in patient-centred } \\
\text { outcomes? }\end{array}$ & 5.05 & 1.22 \\
\hline 8 & $\begin{array}{l}\text { Does the use of ultrasound for peripheral intravenous access } \\
\text { increase success rates? }\end{array}$ & 5.03 & 1.08 \\
\hline 9 & $\begin{array}{l}\text { Does the use of ultrasound in shocked patients result in changes to } \\
\text { clinical management? }\end{array}$ & 4.70 & 1.24 \\
\hline 10 & $\begin{array}{l}\text { Is the use of ultrasound during fracture reduction associated with } \\
\text { reduced rates of re-manipulation? }\end{array}$ & 4.67 & 1.19 \\
\hline 11 & $\begin{array}{l}\text { Is the use of ultrasound to guide femoral nerve blocks associated } \\
\text { with reduced complications / better analgesia? }\end{array}$ & 4.66 & 1.21 \\
\hline 12 & $\begin{array}{l}\text { Is the use of a back slab to treat toddler's fractures associated with } \\
\text { pain reduction? }\end{array}$ & 4.63 & 1.37 \\
\hline 13 & $\begin{array}{l}\text { What dose of dexamethasone (oral or intramuscular) is associated } \\
\text { with better patient outcomes in the management of croup in } E D^{+} \text {? }\end{array}$ & 4.60 & 1.14 \\
\hline 14 & $\begin{array}{l}\text { What measures can be put in place to increase parental / carer } \\
\text { confidence and satisfaction with care in the } E D^{\dagger} \text { ? }\end{array}$ & 4.44 & 1.30 \\
\hline
\end{tabular}

${ }^{\dagger} \mathrm{ED}=$ emergency department; ${ }^{\ddagger} \mathrm{POCUS}=$ point of care ultrasound; ${ }^{8} \mathrm{CRP}=\mathrm{c}$-reactive protein; ${ }^{9} \mathrm{CT}=$ computed tomography 


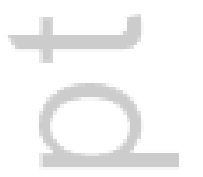


Figures

Figure 1. Delphi survey response rates.

\section{Survey One}

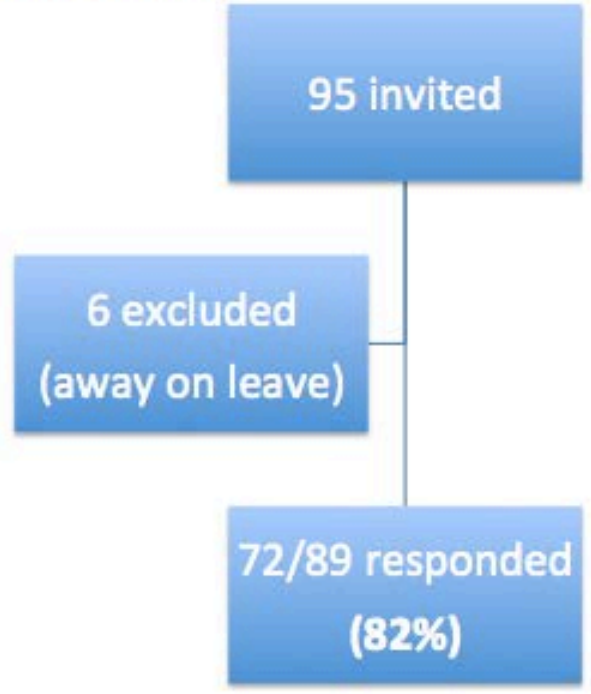

\section{Survey Two}

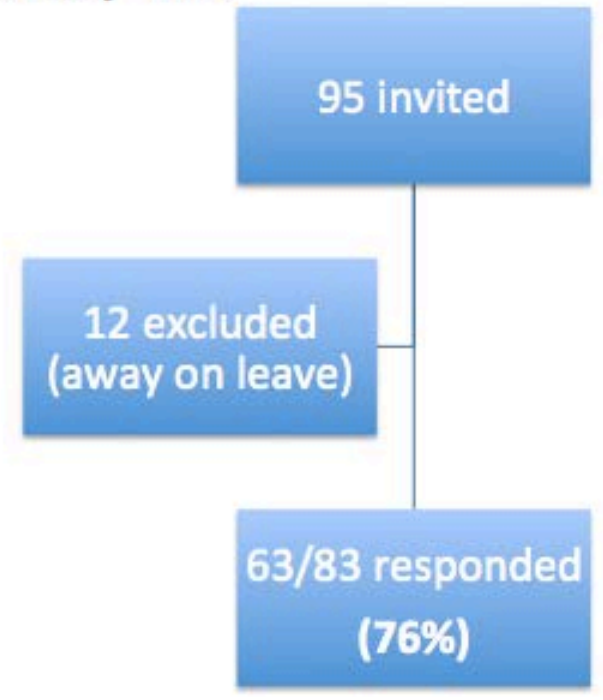

This article is protected by copyright. All rights reserved. 


\section{Delphi assessment of audit and research priorities in an emergency department.}

Sinéad M O’Donnell MD1, Anna Carison1, Jessica Adams1, Elliot Long PhD1,2, Franz E Babl MD 1-3

1 Royal Children's Hospital, Melbourne.

Address: Emergency Department, Royal Children's Hospital, 50 Flemington Rd, Parkville, VIC, 3052, Australia.

2 Murdoch Children's Research Institute, Melbourne.

Address: 50 Flemington Rd, Parkville, VIC, 3052, Australia.

3 Department of Paediatrics, Faculty of Medicine, Dentistry and Health Sciences, University of Melbourne, Melbourne.

Address: Grattan St, Parkville, VIC, 3010, Australia.

AUTHOR'S CONTRIBUTIONS: AC and SOD submitted the ethics application. SOD, AC, JA and EL recruited participants. SOD and $A C$ completed the data entry and revision of this data. SOD, AC, JA, EL and FEB reviewed and amended the project protocol as appropriate and prepared the audit and research topics titles for the second survey. FEB conceived the idea of the project, reviewed data and edited the written versions of the paper.

RUNNING TITLE: Audit and research priorities in an ED.

ADDRESS OF RECRUITING INSTITUTION: Royal Children's Hospital, 50 Flemington Rd, Parkville, VIC, 3052, Australia.

CORRESPONDING AUTHOR:

Dr. Sinéad O'Donnell

Emergency Department

Royal Children's Hospital

Flemington Rd

Parkville

Victoria 3052

Australia

Phone 61393456153

Fax 6139345600

Email sinead.o'donnell@rch.org.au

WORD COUNT: Abstract: 236

Main Text: 2,344 (excluding figures, tables and references)

This article is protected by copyright. All rights reserved. 


\section{University Library}

\section{- M M I N E R VA A gateway to Melbourne's research publications}

Minerva Access is the Institutional Repository of The University of Melbourne

Author/s:

O'Donnell, SM;Carison, A;Adams, J;Long, E;Babl, FE

Title:

Delphi assessment of audit and research priorities in an emergency department

Date:

2020-02-05

Citation:

O'Donnell, S. M., Carison, A., Adams, J., Long, E. \& Babl, F. E. (2020). Delphi assessment of audit and research priorities in an emergency department. EMERGENCY MEDICINE AUSTRALASIA, 32 (4), pp.556-561. https://doi.org/10.1111/1742-6723.13453.

Persistent Link:

http://hdl.handle.net/11343/275375 